\title{
Las condiciones determinantes del desarrollo económico en los países posbélicos periféricos: El caso de Ruanda y República Democrática del Congo.
}

\author{
The determining conditions of economic development in \\ peripheral post-war countries: The case of Rwanda and the \\ Democratic Republic of the Congo.
}

\author{
Etienne Mulumeoderhwa Mufungizi \\ Facultad de Economía y Relaciones Internacionales / Universidad Autónoma de Baja California \\ (MÉXICO) \\ CE: etienne.mulumeoderhwa@uabc.edu.mx
}

DOI: $10.32870 /$ sincronia.axxiii.n76.34b19

Esta obra está bajo una Licencia Creative Commons Atribución-NoComercial 4.0 Internacional

Recibido: 19/03/2019

Revisado: 22/05/2019

Aprobado: 18/06/2019

\section{RESUMEN}

Después de la Guerra Fría, combatir la brecha entre el Norte desarrollado y el resto del mundo en vías desarrollo, había definido la cooperación entre los Estados. Aunque ciertos logros fueron conseguidos, actualmente algunos retos quedan pendientes en materia de crecimiento económico, desarrollo y consolidación de los Estados posconflictos.

La finalidad de este estudio consiste en determinar los procesos históricos, políticos y las condiciones del desarrollo económico en los países de la periferia posbélicos, específicamente los casos de Ruanda y República Democrática del Congo, los cuales han sostenido un crecimiento económico durante el período posbélico. El argumento principal sostiene que las reformas 
institucionales y los gastos prudentes de los gobiernos son las condiciones del desarrollo económico en los países posconflictos periféricos.

Se ha evidenciado que el crecimiento económico de los países aquí abordados, no responde a las teorías económicas tradicionales sino que depende de la gobernanza local posconflicto. También se ha encontrado que los gobiernos ruandeses y congoleses posbélicos, han puesto sus esfuerzos en la cooperación para erradicar los grupos armados; por ello, se ha utilizado un método comparativo para entender los procesos históricos y políticos de los conflictos en Ruanda Y República Democrática del Congo.

Palabras clave: Posconflicto. Desarrollo. Crecimiento económico. Centro-Periferia.

\section{Abstract:}

After the Cold War, fighting the gap between the developed North and the rest of the developing world, had defined cooperation between States. Although certain achievements were achieved, some challenges remain today in terms of economic growth, development and consolidation of postconflict States.

The purpose of this study is to determine the historical and political processes and the conditions of economic development in the post-war periphery countries, specifically the cases of Rwanda and the Democratic Republic of the Congo, which have sustained economic growth during the post-war period. The main argument holds that institutional reforms and the prudent spending of governments are the conditions of economic development in peripheral post-conflict countries.

It has been shown that the economic growth of the countries addressed here does not respond to traditional economic theories but depends on local post-conflict governance. It has also been found that the post-war Rwandan and Congolese governments have put their efforts into cooperation to eradicate the armed groups; therefore, a comparative method has been used to understand the historical and political processes of conflicts in Rwanda and the Democratic Republic of Congo.

Keywords: Postconflict. Development. Economic growth. Centre-periphery. 


\section{Acercamiento al estudio del Centro-Periferia}

El estudio de la estructura económica global se divide en dos zonas: de desarrollo y subdesarrollo. R. Prebisch mostró que el sistema económico mundial está formado por el Centro Y Periferia, enfoque que fue defendido después por la teoría de Dependencia y del desarrollo desigual en los años cuarenta. Este modelo (a diferencia de los modelos económicos ortodoxos que se centraban, por ejemplo, en los ingresos per cápita para clasificar a las economías, el modelo de centro y periferia) se interesó en los factores de productividad.

El Centro y Periferia, como enfoque, se interesó en la producción y quién es el individuo que produce para exportar, lo que ayudó en entender la asimetría que existía en los dos polos económicos del planeta. Dio cuenta que el Centro concentraba en sí la mano de obra calificada y las manufacturas, mientras que en la Periferia abundaba la mano de obra no especializada productora de materias primas. Dentro de esas zonas del sistema económico mundial, los Estados pertenecen y participan en las organizaciones como unidades heterogenias.

Tomados en forma de unidad, cada Estado es una entidad física, biológica o social y homogénea; también en cada país, existen algunos elementos estables organizados que evolucionan en la misma dirección y otros son autónomos (Chevallier, 1978). Dichos elementos son la historia, la política y la sociedad.

En efecto, la organización del sistema internacional se parece a cualquier otro sistema según E. Morín (1977) en donde cada país presenta una doble característica: ecológica e idéntica (p. 202205). Esta doble característica permite al Estado consolidar los vínculos con otros semejantes dentro del sistema. En este contexto, las condiciones del desarrollo de un país implican una correlación entre lo externo y lo interno, es decir, entre la parte integrada a lo organizacional y, la parte controlada hacia adentro. El desarrollo es consecuencia de las interacciones internas y externas de los actores.

Así, los polos económicos Centro-Periferia se han construido sobre las interacciones ambivalentes a lo largo de su historia, no fue un proceso que se haya desarrollado de manera 
espontánea. En esas relaciones, algunos Estados prefieren que permanezca el status quo del sistema y otros buscan sobrevivir en una economía que no les favorecen pero del que dependen de ella. Esta realidad explica por qué se comportan así los Estados en el sistema internacional: introvertidos y extrovertidos, los introvertidos tienen los medios para protegerse de las injerencias externas, mientras que los extrovertidos los carecen.

Según S. Amín (2010), en los países de la periferia, existe una contradicción política y social debido a que esos países son incapaces de llevar a cabo solos sus programas de desarrollo, a excepción de China, Corea del Sur, algunos países del sudeste de Asia, India y ciertos países de América Latina (p.16). Esta situación marginaliza a los países periféricos porque carecen de proyectos de estrategias de desarrollo; en consecuencia, los países centrales deciden por ellos. Desafortunadamente, los países centrales piensan por los periféricos (Amín, 2010) y toman la iniciativa en algunos programas vitales, tal es el caso de la Unión Europea con África y de los Estados Unidos con el Medio Oriente e Israel (p.16-17).

Los países del centro aprovechan de su capacidad material e inmaterial para mantener a los países periféricos en situación de dependencia, lo que debilita aún las decisiones políticas en la periferia. Por eso, el modelo centro-periferia que plantean Jacques Chévallier (1978) como Amín (2010), ofrece un cuadro conceptual adecuado para analizar la relación que une esas zonas del sistema internacional y por ende, permite entender las ramificaciones del poder dentro del mismo sistema internacional, es decir, que el centro tiene una concepción diferente de la que la periferia se tiene de sí misma.

Cabe mencionar que los países de la periferia concretan su muerte en el momento de proyectarse hacia el exterior, debido a que no tienen la capacidad material e inmaterial para competir con los países de centro. Por otro lado, existe una contradicción en el cumplimiento de los grandes proyectos de desarrollo y la naturaleza de los compromisos de los actores periféricos. La división de la clase política, el distanciamiento y las tensiones entre actores son producto de ese incumplimiento junto con la falta de continuidad institucional. 
Las contradicciones entre los proyectos de desarrollo y la naturaleza de los compromisos, no se sitúan únicamente a nivel del Estado, están también en el nivel político: en el estatal, el Estado parece guardar el monopolio de los códigos para imponer la autoridad en su territorio; en el político, existe una división entre el centro y la periferia dentro de un mismo Estado, es decir entre la élite que gobierna y el resto de la ciudadanía. En ese último, la élite institucionalizada escapa al control del Estado, una élite desintegrada de los demás grupos sociales que controla la economía y la vida política de la periferia.

En efecto, la estructura estatal y económica establecida en la periferia es causa del desarrollo desigual. Construye dentro del mismo país ciudades desarrolladas con acceso a los servicios públicos y campesinos abandonados (Chevalier, 1978; Furtado, 1964). En ese marco, la evolución del desarrollo es un antagonismo de los intereses de clases. Éste tiene un carácter histórico heredado de la colonización (Furtado, 1964, p. 37). El análisis de Furtado (1964) y de Chevallier (1978) muestra claramente que los países periféricos se construyen sobre bases sociopolíticas y económicas desequilibradas.

La estructura desequilibrada va más allá de la dialéctica centro periferia. Es observable dentro de un mismo Estado, es la voluntad política para implementar el desarrollo socioeconómico, la acumulación de los bienes para la élite y el fracaso de los esfuerzos gubernamentales. La dialéctica periférica es disfuncional en relación al sistema nacional e internacional; que en el escenario internacional, favorece la dependencia de los Estados periféricos; los individuos unos a otros y al mismo tiempo hace imposible la toma de decisiones.

Hasta aquí puede afirmarse que el modelo centro periferia tiene dos dimensiones complementarias: por un lado, la inserción en la periferia de un modelo político ajeno a la realidad y por el otro, el estancamiento interno en la toma de decisiones.

A la Comisión Económica para América Latina (CEPAL), se le atribuye la teoría centroperiferia, término compuesto por Raúl Prebisch, uno de los padres del modelo de desarrollo basado en dependencia, para describir los dos polos del sistema internacional. En cuestiones de poder, Carlos Escudé (2012) ofrece un estudio sobre el realismo periférico que se traduce en ecuaciones de 
poder entre los países del centro y los de la periferia. La tesis que defiende este autor afirma que "cuanto más débil es un país, más bajo es el umbral de autonomía externa a partir del cual la libertad de los ciudadanos debe forzosamente disminuir" (p.19).

Desde la perspectiva analítica de Carlos Escudé, la cuestión centro periferia es una ley universal para mantener el equilibrio meta-político de los Estados. En este equilibrio, las potencias de centro, controlan bajo bloqueos político-económicos, las políticas exteriores de los países periféricos (Amín, 2010; Escudé, 2012). Eso significa que económicamente el centro domina los espacios financieros y, políticamente, reconoce la soberanía de los países periféricos. La cuestión de soberanía parece una regla sin importancia al momento de tener el control sobre economía y los ciudadanos de los países en vía de desarrollo.

La desigualdad traducida en términos de poder es la característica del sistema internacional. Dicha desigualdad es material y demográfica, tal vez sólo el Estado cosmopolita y utópico planteado por Kant podía acabar con la desigualdad internacional (Kant, 1998 p. 15). Este Estado que promovería la igualdad, según este autor, tendría un carácter supranacional que eliminaría todas las barreras políticas, sociales y económicas entre los Estados.

Para Kant, el carácter jerárquico es el que mejor describe el sistema internacional, idea que hoy en día, no ha desaparecido del escenario internacional. Observando tranquilamente la composición del Consejo de Seguridad de las Naciones Unidas, es posible darse cuenta que unos cuantos países deciden el futuro de toda la organización. Esos países disponen el monopolio del poder y son tomadores de las decisiones importantes aunque, reconocen el carácter igualitario en materia de soberanía (Organización de las Naciones Unidas, 1945, art. 2.1).

Considerando lo planteado hasta aquí, los países periféricos representan un grupo marginal en sus estructura económica, debido a que son países presentados frecuentemente ante la opinión pública como los grandes perjudicados por la globalización económica. Sin embargo, esa marginalidad no debe ser un freno del desarrollo, porque lo que hoy en día viven, existió como problema en los países de centro. Desde este planteamiento, las condiciones de desarrollo para la periferia suponen un proceso de continuas y sucesivas inversiones; de la misma forma, el desarrollo 
económico en la periferia es proceso social, un esfuerzo e imaginación de planeación que incluye los factores sociales y económicos.

Esta primera parte mostró las debilidades político-económicas de la periferia en comparación con el centro. Esa situación se ha dado en un mundo globalizado donde una parte de la historia ha manifestado su fracaso para implementar las condiciones necesarias de creación de riqueza y favorables para el desarrollo. Algunos estudios han defendido que las condiciones de desarrollo en la periferia tendrán que pasar por la industrialización y la liberalización del comercio como se verá en el siguiente párrafo.

\section{El crecimiento socioeconómico como condición del desarrollo}

El crecimiento socioeconómico se entiende como el aumento de la riqueza y del capital humano; sus implicaciones son el intercambio y comercio internacional que es impulsado por el capital, trabajo e ingreso (Fortes y Ruerda, 2001, p. 21; Keynes, 1976, p. 12). La distribución de este último favorece el crecimiento de la economía y la calidad de vida de los habitantes.

Lo anterior apunta a un mundo donde los ciudadanos tienen una mayor preponderancia en el actuar de los gobernantes de los cuales las políticas económicas incentivan la producción y el consumo (Aguado, Echebarría y Barrutia, 2009). De esta forma, el crecimiento económico corresponde a un proceso multidimensional que incluye lo social, lo político y lo económico. La distribución de los ingresos es una combinación de esfuerzos entre los actores sociopolíticos y los mercados, llevada a cabo a través del cumplimiento de las políticas públicas.

En ese proceso, la interacción de los actores es de suma importancia para mitigar los conflictos de intereses entre los grupos, esto significa poder diferenciar los intereses del mercado, de la ciudadanía y del gobierno. Otra condición del crecimiento económico es la creación de empleo impulsado por la inversión en tecnología y la especialización, lo que implica una continua inversión en la investigación y la formación del capital humano para la promoción del empleo. En concordancia con Sánchez (2014), los países que han orientado sus políticas económicas hacia la 
formación del capital humano especializado, son los que han aprovechado de los recursos presentes en sus territorios (p.3).

En efecto, R. Malthus (1970), ofrece un estudio abundante sobre la disponibilidad de los recursos y el control de la demografía. Para él, esos dos elementos son principales condiciones del crecimiento económico y por lo tanto, del desarrollo. Sin embargo, el aumento de la demografía puede ser un freno al crecimiento económico porque implica escasez y el consumo de los recursos disponibles. Otros autores han tomado camino diferente pensando que las políticas de desarrollo centradas en el mercado han creado la desigualdad económica dentro de los Estados, regiones y a nivel global.

Stigliz (2012), por ejemplo, advirtió que los resultados de las teorías de desarrollo basadas en el crecimiento económico han sido insuficientes para explicar la desigualdad social (p.80), debido a que los países son incapaces de regular los mercados por las asimetrías que éstos crean, lo que afecta a la sociedad (Stigliz, 2011, p. 81). En este sentido, las consecuencias del laisser faire (dejar hacer) de los mercados, son devastadoras y el argumento del crecimiento a largo plazo es insostenible. Esto se ha manifestado después de los años sesenta cuando la mayoría de los países asiáticos y africanos consiguieron su independencia. La atención de los académicos se enfocó en la desigualdad social y en la políticas del crecimiento económicos, defendiendo la cooperación internacional para el desarrollo entre los países de centro con los de periferia, para acabar con la brecha entre las dos zonas económicas. Dicho enfoque de los académicos fue conocido como estudio del desarrollo, cuyos pioneros fueron Meier y Seer.

Para ellos, las teorías del crecimiento económico crearon un pensamiento estático que sólo se limitó a la asignación de los recursos y al intercambio (Meier y Seers, 1984 p. 20). Fueron los primeros en plantear los modelos del crecimiento endógeno basado en la formación del capital humano, la transferencia del conocimiento y el progreso técnico, lo que implicaba para ellos la inversión de los países en la investigación, formación de empresas estatales e instituciones para generar la innovación. 
Estos estudios permitieron exponer las desigualdades que existían entre los países llamados "desarrollados" y los países "en vías desarrollo", estos últimos, Prebisch les denominó países periféricos. Este académico desarrolló la teoría del centro-periferia que defendía la idea de la imperfección de los mercados en los países subdesarrollados. Su punto de partida reposaba sobre la división internacional del trabajo y la dificultad de los países en vías de desarrollo para acceder a los mercados. Se especializó en los recursos naturales y en los países con pocos componentes tecnológicos (Aguado, Echebarría y Barrutia, 2009 p.97).

Por su parte, Meier y Seers (1984) establecen que:

[...] la hipótesis de Prebisch, analiza el deterioro de la relación real de intercambio entre los países del centro y de la periferia a favor de los primeros, especializados en la exportación de las manufacturas alejándose de los precios de las materias primas. (p. 21).

Después de las fallas en la aplicación de las teorías de desarrollo en algunos casos, se introdujeron nuevos paradigmas estabilizadores, tales como los equilibrios económicos, la confianza en el mercado, los ajustes estructurales y la liberalización de la economía. (Aguado, Echebarría y Barrutia, 2009, p. 99).

Es el caso de Bauer (2000), cuando observa que "el desempeño económico depende de factores personales, culturales y políticos, de las aptitudes y motivaciones de las personas, y de instituciones políticas y sociales" (p. 29), incentivan la entrada del capital de forma local pero también de su importación desde el exterior. En cuanto a la escasez de la tierra, "la comida se [obtiene] a través de la agricultura intensiva o de la exportación de otros bienes" (p. 29). Desde el punto de vista económico, este autor, pone énfasis en los actores locales para promover el desarrollo económico actuando racionalmente y con prudencia.

\section{Cuadro 1: Comparación de los diferentes modelos de desarrollo socioeconómico}

\begin{tabular}{|c|c|c|c|c|}
\hline $\begin{array}{c}\text { Clásicos } \\
\text { (Ricardo, }\end{array}$ & $\begin{array}{c}\text { Keynes y los } \\
\text { poskeynesianos }\end{array}$ & Neoclásicos & Neoliberales & $\begin{array}{c}\text { Crecimiento } \\
\text { endógeno }\end{array}$ \\
\hline
\end{tabular}




\begin{tabular}{|c|c|c|c|c|}
\hline Malthus...) & (Robinson) & & & \\
\hline Laisser faire & $\begin{array}{l}\text { Tasa de ahorro, } \\
\text { concurrencia } \\
\text { imperfecta, } \\
\text { rendimiento } \\
\text { creciente, } \\
\text { apertura }\end{array}$ & $\begin{array}{l}\text { El crecimiento } \\
\text { depende del } \\
\text { progreso } \\
\text { técnico, } \\
\text { concurrencia } \\
\text { perfecta... }\end{array}$ & $\begin{array}{l}\text { Liberalización } \\
\text { económica, } \\
\text { reforma del } \\
\text { Estado, } \\
\text { apertura y } \\
\text { externalización } \\
\text { de los } \\
\text { mercados }\end{array}$ & $\begin{array}{l}\text { Accumulación } \\
\text { del capital físico, } \\
\text { humano } \\
\text { conocimiento, } \\
\text { ganancias, } \\
\text { externalización... }\end{array}$ \\
\hline
\end{tabular}

Fuente: Elaboración propia con datos de Fortes y Rueda, 2011.

Es cierto, que en algunos países las políticas de desarrollo han dado resultados positivos y en otros no. Lo anterior se debe a la influencia cultural económica en la que se desarrolla cada país.

Cabe señalar que existe un debate respecto a la exportación de los modelos económicos de desarrollo exitosos en países desarrollados en relación a los países en vías de desarrollos, denominados consenso latente que aun divide a los expertos en el tema de desarrollo (Fortes y Rueda, 2011, p.36). Ese debate aún no ha generado un acuerdo sobre las causas del éxito o del fracaso de los modelos económicos de desarrollo.

Vale la pena preguntarse ¿Por qué en algunos países han fracasado las políticas socioeconómicas de desarrollo? ¿El fracaso ha sido causado por la implementación de las políticas de desarrollo o por los políticos?

Es posible, desde luego, que el éxito o fracaso de los modelos del desarrollo no estén ligados a la cultura o a la región geográfica. Los Estados logran la aplicación de los modelos de desarrollo socioeconómico cuando tienen instituciones adecuadas, esto es, que están preparados para los sistemas de cambios entre actores políticos dentro de sus territorios. 
Hay otro factor importante del desarrollo que está ligado al ser humano: la construcción de un Estado de derecho, cuyo desarrollo tiene como componente ineludible la persona misma (Acemoglu y Robinson, 2015).

En este contexto, en 1990, el Programa de las Naciones Unidas para el Desarrollo (PNUD), introdujo por primera vez en su informe los conceptos "desarrollo sostenible" y más tarde "desarrollo humano" lo que fue una consideración importante del ser humano dentro de los factores del desarrollo. La preocupación de esta institución de apoyo al desarrollo, se enfocó más en el crecimiento económico, incluyendo la calidad de vida y la creatividad.

En efecto, el centrarse en la búsqueda de la calidad de vida, es un punto medio entre los modelos de desarrollo socioeconómico y la gobernanza local. Este punto de unión está ubicado en el lugar que ocupa el ser humano en las políticas públicas (Fortes y Ruerda, 2011) y es a partir de ese planteamiento que puede asociarse el Estado, ciudadanía y mercado para la gestión de los asuntos públicos para el desarrollo, mejor conocidos como gobernanza local.

Es menester reconocer que la gobernanza no terminaría con el subdesarrollo, sino que favorece la participación de la ciudadanía en las políticas públicas. También la gobernanza local ofrece herramientas adecuadas para el progreso de la democracia y rendimiento de cuentas en la transparencia.

Junto a la democracia y la transparencia, la gobernanza promueve factores positivos no económicos para el desarrollo: las libertades civiles y los derechos humanos (Fortes y Rueda, 2011 p. 67). Estos permiten medir el progreso en término de desarrollo económico y humano y, de las libertades políticas en un país determinado.

A lado de los estos factores no económicos positivos, existen otros factores no económicos negativos y dañinos del desarrollo, a decir, la corrupción y la inestabilidad política que afectan los esfuerzos de los gobiernos y disminuyan los gastos del sector educativo y desalientan las inversiones privadas en los sectores productivos de la economía. De acuerdo con Raimundo Soto (2003), la corrupción "reduce la efectividad y la calidad de las políticas económicas [...], distorsiona el diseño y la aplicación de las regulaciones [entraba y ensucia] el accionar de la justicia” (pp. 23-62). 
Desde esta perspectiva, la reducción del crecimiento socioeconómico, la inestabilidad política, la desigualdad y la falta de prosperidad, son efectos de la corrupción y de la inestabilidad política en una sociedad (Mauro, 1995). Para este autor, el disfuncionamiento de las instituciones frena la innovación tecnológica, genera la burocracia y el acceso a las licencias ilegales en la adquisición de las concesiones. Este fenómeno destruye la economía, sofoca el accionar de las empresas privadas y construye normas favorables a la élite política y económica.

\section{El periodo posconflicto en Ruanda y República Democrática del Congo}

Para Benítez Jiménez (2016), la construcción del período posconflicto ${ }^{1}$ se fundamenta en la movilización de los actores políticos, sociales, religiosos y beligerantes para defender los derechos humanos (pp. 141-166). Después de los conflictos de 1990 a 2002, en Ruanda y República Democrática del Congo, el proceso democrático y de estabilización política ha evolucionado positivamente. Aunque continúan algunas tensiones políticas en estos últimos países debido a la presencia de las milicias extranjeras y locales, éstas han disminuido en la mayoría de las regiones de los países que se abordan en este estudio.

Después de los conflictos tanto en Ruanda como en el Congo, la construcción de la paz y la estabilidad político-económica, ha sido considerada como condiciones para promover el desarrollo. Juntar los actores implicados en la meza de negociación fue un mecanismo regional de terminar con los problemas de seguridad y fundar bases para para el desarrollo económico. Otras vías adaptadas fueron la desmovilización de los grupos armados y su integración en la vida civil. Uno de los objetivos principal de esos mecanismos fue garantizar los derechos a la verdad, la justicia y la reparación.

En Ruanda por ejemplo, el periodo posconflicto, impulsó las instancias internacionales para juzgar a los actores de crímenes de genocidio. Dicho proceso de justicia se extendió de adentro hacia afuera del país, lo que llevó al arresto y juicio de ex militares y civiles, pero que representó un

\footnotetext{
${ }^{1}$ El pos-conflicto es aquel período de tiempo que se inicia con el cese de hostilidad entre las partes previamente enfrentadas, la construcción de la paz prepara el terreno desde mucho antes.
} 
paso importante para llevar a cabo una reconstrucción social, democrática y económica (Benavides, 2011 p. 5). Para este autor, la justicia en la época de transición cobra su importa porque con ella los actores entienden los problemas que se presentan durante la transición democrática o deciden cómo enfrentar los crímenes cometidos durante el período de conflicto. Cabe mencionar que los actores relevantes para defender la justicia durante la transición posconflicto son los defensores de los derechos humanos.

Los dos países de estudio pertenecen a la categoría de las economías periféricas y son posconflictos. Hay que reconocer que el posconflicto puede aplicarse a cualquier país; la elección de este caso se justifica por la interconexión de sus conflictos siendo Ruanda el origen principal de los conflictos en su vecino Congo, contexto que ha generado tensiones entre la élite política de ambos países y ha dificultado la aplicación de la justicia, paz, castigo y perdón, aunque las experiencias de justicia en época de transición tienen elementos en común en países diferentes, disponen procesos complejos y únicos como la reparación de las víctimas, los intereses contrapuestos de las partes y la justicia etc. (Benavides, 2011).

\section{La República de Ruanda}

Ruanda es un Estado de 26, 338 kilómetros cuadrados y resulta ser uno de los países densamente poblado de África. Su estructura social se compone de tres grupos étnicos en mayoría Hutu 84\%, tutsi $15 \%$ y $1 \% T w a^{2}$ o pigmeos. Sobre esta división social se construyeron la vida política y económica dominada por la etnia tutsi.

La etnia Twa fue la primera en instalarse en Ruanda y en toda la región de los grandes Lagos. Ellos vivían de la caza y más tarde llegaron los Hutus, un grupo bantú que impuso a la población autóctona. La llegada de los Tutsi fue lenta, progresiva y expansionista, en búsqueda de tierra para

\footnotetext{
${ }^{2}$ Los Twa es un pueblo africano que se encuentra en varios países de África Central. Se reconoce pigmeo por referirse a su pequeño tamaño. El un pueblo cazador-recolector. Los grupos más estudiados son los Mbuti de la selva de Ituri en la República Democrática del Congo. Entre los demás grupos están los Aka, Baka, Binga, Éfé, Gok y Twa. Los pigmeos se encuentran en: Ruanda, Burundi, Uganda, República Democrática del Congo, Camerún, Guinea Ecuatorial, Gabón, Congo, Angola, Botsuana, Namibia y Zambia.
} 
la ganadería. Pero a pesar de ello, la convivencia entre los tres grupos fue pacífica. La estructura política puesta en marcha fue la monarquía, el rey podría salir de cualquier los tres grupos sociales.

En el siglo XIX con la llegada de alemanes y luego belgas; Ruanda dejó de ser una monarquía y pasó a ser una colonia belga. Su administración dependía de la administración colonial presente en Congo, ésta reconoció la dominación Tutsi sobre los Hutus ofreciendo más poder a la monarquía aunque carecía del poder político-económico. Continuó la monarquía, pero se volvió un sistema más centralizado y explotador. Se obligó al pueblo a entrar en un sistema obligatorio de identificación en el que se establecía la pertenecía étnica. Los belgas colocaron a la élite tutsi en las posiciones privilegiadas del gobierno, de la estructura social y al acceso a la educación con el control de la Iglesia. Situación que dejó a los Hutus en un nivel social muy inferior en comparación con los Tutsis.

En 1962 Ruanda consiguió su independencia de Bélgica; a través de las elecciones, la etnia hutu alcanzó por primera vez al poder. Juvénil Habyarimana y Grégoire Kayibanda realizaron la primera formación política después de la Manifeste Hutu denominada como la Promoción Social de las Masas (Aprosama). Con la misma lógica, los Tutsis crearon dos partidos políticos, la Unión Nacional Ruandesa (Unar) y la Reunión Democrática Ruandesa (RADER). En 1959 un enfrentamiento sangriento entre los militantes de los partidos hutus con los de los tutsis ocasionó el exilio de los últimos en los países vecinos (Mayra 2002 p. 5).

Posteriormente, la represión que siguió la segunda República de Ruanda, obligó a los tutsis a huir del país y buscar refugio en los países vecinos. Mientras los refugiados de 1959 querían regresar a su país de origen, el gobierno ruandés defendía la idea según había menos tierras para recibirlos:

Esta circunstancia ha producido una fuerte presión demográfica en el último siglo hacia los países vecinos, especialmente Zaire donde viven los banyaruandas y banyamulenges originarios de Ruanda y que han producido problemas de convivencia interétnica en la región fronteriza del Kivu. La falta de espacio ha dificultado además políticas de retorno de exiliados, esenciales para la resolución del conflicto (Pardo y Vacas, 2005, p.17-18) 
En 1988, el descontento de los refugiados los llevó a crear un partido armado desde Ugada denominado Frente Patriótico Ruandés (Fpr). Su finalidad era el derrocamiento de J. Habyarimana, el regreso al país a través de las arma. Tuvieron directamente el apoyo de Uganda, Estados Unidos e Inglaterra. Después de conseguir el apoyo externo, la crisis ruandesa se radicalizó y los acuerdos de paz se transformaron en letra muerta. El Acuerdo de Arusha había abierto un camino a un gobierno de unidad nacional pero lo esfuerzos de la Unión Africana se taparon a la ideología anti tutsi promovida por los hutus extremistas (Mbuyi, 1997). En abril de 1994, la crisis dio lugar al exterminio de los tutsi y de los hutus moderados como consecuencia del asesinato del Presidente Juvénil Babyarimana.

Después del genocidio, el gobierno trabajó para mejorar el acceso a los servicios médicos y educativos, lo que hizo que el país contara con una baja mortalidad infantil. El genocidio de Ruanda, que tuvo lugar en 1994, exterminó a gran parte de la población tutsi. La comunidad internacional coincide que el genocidio fue perpetrado de manera concentrada, sistemática y metódica (Ministerio de Asuntos Exteriores, 2018).

En efecto, sólo el $10 \%$ de la población ruandesa vive en las ciudades. Las ciudades más importantes son Kigali la capital y Butare, el resto de la población es campesina y vive de la agricultura de subsistencia. Uno de los conflictos persistentes en Ruanda posconflicto es la gobernanza local de la tenencia a la tierra, debido al crecimiento demográfico y al retorno de los refugiados. Aunque el país representa mucho progreso en materia de gobernanza no ha logrado a luchar contra la pobreza y la distribución equitativa de los ingresos.

El país ha renovado con la gobernanza local a través de la innovación tecnológica, la educación y las reformas estructurales (Banco Mundial, 2007), esto ha logrado que Ruanda se posicione como uno de los países más atractivos del continente africano, donde hacer negocio es cada vez más fácil, aunque el país no cuente con recursos naturales abundantes. La siguiente gráfica muestra los datos económicos que arrojan una imagen de los esfuerzos de los últimos de años ruandeses. 
Gráfica 1. Los indicadores económicos de Ruanda de 2014-2017.

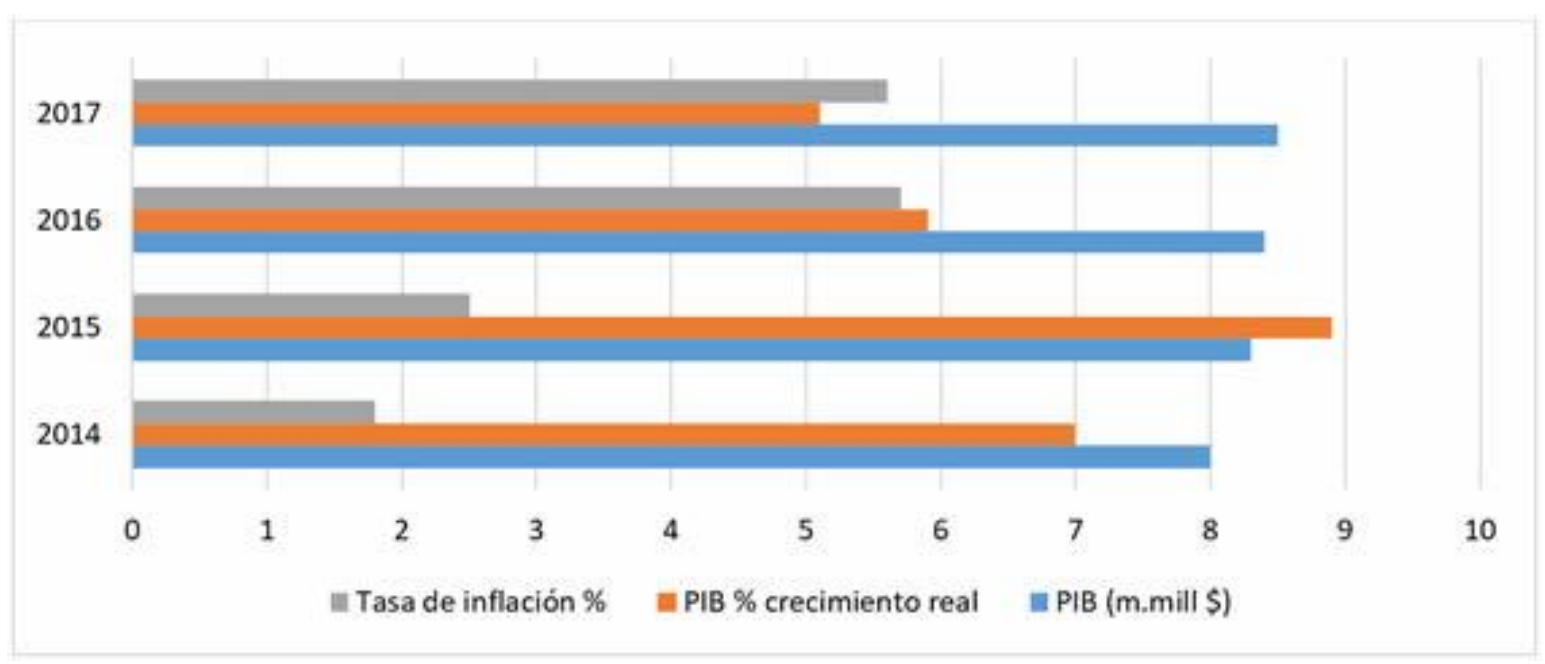

Fuente: Elaboración propia con los datos del Ministerio de Asuntos Exteriores de España, 2018.

Ruanda posconflicto ha puesto en marcha una política económica prudente que ha impulsado un crecimiento económico y logrando que sea uno de los países menos corruptos del mundo. Si el genocidio destruyó las bases económicas del país, el gobierno posconflicto se ha centrado en la reconstrucción y la recuperación de las instituciones lo que llevó a mejorar los resultados económicos e indicadores sociales.

Como resultado de las medidas que las autoridades tomaron para reformar la economía y la gobernanza local entre 2014 y 2017, fue el crecimiento económico anual con un promedio alrededor de 7\%. La pobreza disminuyó pero también la mortalidad infantil. Aumentó la participación de la mujer en la vida política y pública del país. En cuanto a la gobernanza al nivel regional, el gobierno ruandés se ha esforzado en la cooperación con el gobierno congolés para erradicar los grupos rebeldes residentes sin dejar de apoyar militarmente a las diferentes rebeliones en la República Democrática del Congo. 


\section{La República Democrática del Congo}

Los últimos estudios sobre la República Democrática del Congo describe a este país como un elefante dormido, un escándalo geológico en el centro de África. Es verdad que ha sido uno de los países más golpeados del continente, primero por la esclavitud y la colonización, después por las guerras económicas, la destrucción de las sociedades tradicionales, la explotación de los recursos naturales; pero también, existe una República Democrática del Congo que se fundamenta sobre la gobernanza local de la tenencia de las tierras por las comunidades, las capacidades creativas de sus jóvenes, la recuperación de los legados culturales y la innovación en el ámbito socio-económico.

La R. D. Congo es una síntesis de todas estas situaciones. Vivió una de las colonizaciones más inhumanas del siglo XIX, primero, porque fue una propiedad personal del imperador belga Leopoldo II; luego, fuente de riqueza natural de Bélgica. Se independizó en 1960 después de un proceso sangriento que culminó con el asesino de Patricio Lumumba y la llegada al poder de Mobutu Sese Seko, quien instauró una dictadura de treinta dos años hasta a su exilio en 1997 (Arnabat, 2009, p. 4; Péan, 2010, p.24). Mobutu cambió el nombre del Congo con el de Zaire, dejó la explotación de la tierra y de los recursos naturales a las empresas multinacionales.

Después de la caída del régimen mubutista, el país entró en un largo período de guerras y rebeliones. Esas fueron consecuencias de los conflictos pos-Guerra Fría que marcaron a Angola, Uganda y sobre todo, una prolongación de la guerra civil y genocidio ruandés. A la presencia de las milicias extranjeras, se opusieron las etnias tutsi y hutu dentro del territorio congolés, siguió la formación de otras milicias de origen congoleño para proteger sus tierras de la mano de los invasores externos. Esas generalmente carecen de un proyecto político, se nutren de la explotación y la comercialización ilegal de los recursos naturales.

En efecto, otras naciones africanas intervinieron ${ }^{3}$ en lo que hoy en día se considera como la Primera Mundial Africana o la Primera Guerra Secreta de las grandes potencias en África (Péan, 2010). Las tropas de Uganda, Ruanda, Burundi, Zimbabue, Angola y las de la R. D. Congo, se

\footnotetext{
${ }^{3}$ La caída del régimen mubutista se debió en grande parte a la reconfiguración de la política regional que había modificado la tendencia de las décadas anteriores durante las cuales el gobierno de Mobutu Sese Seko intervenía militarmente en Angola (1975), en Chad (1984) y en Ruanda (1990) (Mbuyi, 2009, p. 34).
} 
enfrentaron en ese país hasta al punto de ser llamada la Primera Grande Guerra Africana haciendo un paralelismo con la primera Guerra Mundial que principalmente se vivió en Europa. Las secuelas de las décadas de conflictos han dejado huellas visibles en el país, el deterioro de la gobernanza local de la tenencia de la tierra, los millones de muertos, los desplazados internos y externos, la violación sexual como arma de guerra, etc.

A pesar de lo anterior, la R. D. Congo es un granero del futuro político y económico africano por los siguientes factores: a) su posición geopolítica en el centro del continente, b) inmensa riqueza de recursos naturales, c) la biodiversidad y d) la demografía. Ese país cuenta con una superficie de 2’345,000 km², comparte su frontera con 9 países: Angola, República del Congo, República Centroafricana, Sudán, Uganda, Ruanda, Burundi, Tanzania y Zambia. Si bien ha tenido conflictos, confrontaciones políticas entre los vecinos hasta el llamado escándalo geológico, no ha dejado de ser la codicia de la potencias mundiales (Cattier, 1906).

A diferencia de Ruanda, la R. D. Congo gozaba de una admiración particular de la metrópolis por sus recursos naturales, su posición geoestratégica y diversidad cultural. Actualmente, debido a la falta de la gobernanza local traducida en la gestión razonable de los factores, arriba mencionados, a pesar de ser un país potencialmente rico, tiene la población más pobre del mundo (Mbuyi, 2009, p.32). Si en las demás colonias de Bélgica, la gobernanza local se basó en el fortalecimiento de la monarquía, en la R. D. Congo la construcción del Estado colonial se fundamentó en la supuesta superioridad de algunas etnias sobre otra. La consecuencia de eso fue el odio entre los Baluba, los Lulua en la provincia de Kasai y los nativos de Katanga, entre los Bakongo y los Bangala.

Las fallas lejanas de la gobernanza local en ese país tienen sus orígenes en la no preparación de los cuadros administrativos autóctonos durante la colonización. También puede explicarse por la irresponsabilidad de los gobiernos que siguieron después de la independencia, representantes de los intereses de las grandes potencias en el país. Los años noventa fueron la expresión de la desaparición de la autoridad del Estado en el territorio nacional y la desorganización del comando del ejército mubutista. El deterioro de la infraestructura, la espoliación del derecho de acceso a la 
tierra, la destrucción de la industria minera y otros factores endógenos, crearon una cultura de la depredación de los recursos del país.

La toma de poder por las armas de la Alianza de Fuerza Democrática de Liberación del Congo (AFDL), marcó un periodo de transición democrática. Los aliados de Laurent Désiré Kabila, Ruanda y Uganda no tardaron en explotar el oro, diamante y coltán congoleño. Los años que siguieron a los años noventa constituyen un periodo de transición democrática dirigida por los mismos actores implicados en las repetidas guerras y la destrucción estructural país. En resumen, de acuerdo con Ndaywell (1998), la historia de ese país ha sido caracterizada por una sucesiva ola de violencia: tanto por parte del Estado, como por la misma masa popular que terminó en un enfrentamiento armado (pp. 418-419).

Hoy en día, la R. D. Congo se encuentra en proceso de consolidación de la gobernanza local de sus instituciones y ha tenido un efecto positivo en el plano económico. El gobierno ha puesto en marcha una política macroeconómica ordenada y ha aprobado medidas para la racionalización del clima de negocios y la lucha contra la corrupción. Sin embargo, la caída de los precios minerales de 2017 y 2018, en materia de producción y exportación de las materias primas, en especial el cobre y el cobalto, golpearon el crecimiento económico de los últimos años.

Gráfica: El crecimiento económico de la R. D. Congo de 2013-2018

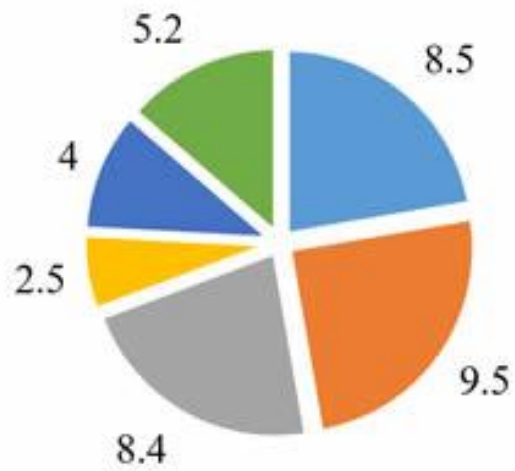

$$
\begin{aligned}
& =2013 \\
& =2014 \\
& =2015 \\
& =2016 \\
& =2017 \\
& =2018
\end{aligned}
$$

Fuente: Elaboración propia con datos del Banco Central del Congo, 2018. 
Como se mencionó anteriormente, la caída y la fluctuación de los precios de las materias primas tuvieron repercusiones en el crecimiento económico del país, que atrajo como consecuencia la disminución del financiamiento de la investigación y de la explotación minera; asimismo, como cualquier país posbélico, la R. D. Congo reconstruye su sistema político y administrativo que fue destruido en las últimas décadas. Después de la transición, y como estipula el acuerdo de Sun-City de 2002, un nuevo gobierno fue puesto en marcha, dirigido por Joseph Kabila, que fue electo en 2006 y 2011. El país no cuenta con una larga experiencia de democracia y sus líderes políticos tienen mucho que aprender de la gobernanza local en todos los aspectos. En consecuencia, el fortalecimiento de la gobernanza local, para la tenencia de la tierra, el sistema de acceso a la información y la respuesta a la demanda de la población, son los factores que consolidarán el Estado en sus fronteras.

Para concluir, en la última década, los países Ruanda y República Democrática del Congo, han superado los años de conflictos armados y han orientado sus políticas hacia la cooperación para el desarrollo y crecimiento económico. Se ha demostrado que los países periféricos carecen de un capital humano especializado, lo que explica por qué los países de estudio han colaborado con actores nacionales e internacionales para llevar a cabo las reformas institucionales necesarias.

En términos económicos, los dos países han superado las expectativas regionales en cuanto al crecimiento económico; los conflictos armados han disminuido a pesar de algunas tensiones políticas en la República Democrática del Congo y uno de los factores que explica el cambios socioeconómico, es el aumento de las inversiones, generación de empleo y la elevada demanda de materias primas en el mercado internacional.

\section{Referencias}

Acemoglu, D. y Robinson, J., A. (2015). Los orígenes del poder, la prosperidad y la pobreza, por qué fracasan los países, México: Ed. FTS. A de C.V.

Aguado, I.; Echebarria, C.; Barrutia, J. M. (2009). El desarrollo sostenible a lo largo de la historia del pensamiento económico. Revista de Economía Mundial. (21), 87-110. 
Amín. S. (2010): Escritos para la transición, La Paz: Ed. Lourdes Montero, Gonzalo Gozalvez.

Arnabat, X., L. (2009). “Le Congo, l'Afrique, une question pendante" In Mbuyi, K. \& Luque. (coord.): La République Démocratique du Congo. La droit humains, les conflits et la construction/destruction de I'Etat, Barcelona: ed. Fundació Solidaritat UB et Inrevés. P.4.

Cattier, F. (1906). Étude de la situation de l'E.I.C., Paris: Ed., A. Pédone.

Banco Mundial, (2007). Rwanda: recuperación, rehabilitación y esperanza, Recuperado de http://www.bancomundial.org/aif. Consultado el Mayo de 2019.

Bauer, P. T. (2000). From Subsistence to Exchange and Other Essays. Princeton, New Jersey: Princeton University Press, p.29.

Benavides, F. S. (2011). Justicia en épocas de transición conceptos, modelos, debates, experiencias, Barcelona: Institut Català Internatiocional per la Pau.

Chevallier, J. (1978). Le modèle centre/périphérie dans l'analyse politique. En Centre, périphérie, territoire. France: Ed. Presse Universitaire Française, p. 3-131.

Escudé, C. (2012). Principios del realismo periférico: una teoría argentina y su vigencia ante el ascenso de China, Buenos Aires: Lumière.

Fortes, A., I. y Rueda, A., G. (2011). Factores determinantes del desarrollo económico y social, España: Universidad de Almería.

Keynes, J. M. (1976). Teoría general de la ocupación, el interés y el dinero. México: Fondo de la Cultura Económica

Malthus, T.R. (1970). Primer Ensayo sobre la población. Madrid: Alianza

Mayra, R. (2002). La guerra civil en Ruanda de 1990 a 1994 (Tesis), México: Colegio de México.

Meier, G., M.; Seers, D. (1984). Pioneros del desarrollo. España: Tecnos

Ministerio de Asuntos Exteriores (2018), Ficha país, Ruanda. España: Oficina de Información Diplomática.

Morín, E. (1977). La méthode: la nature de la natur. Paris: Ed. Seuil

Mbuyi, K. (1997). El drama de la región africana de los Grandes Lagos: orígenes, causas, protagonistas y perspectivas. En África América Latina, Cuadernos: Revista de análisis Sur-Norte para una cooperación solidaria, (27-28), 179-205.

Mbuyi, K. (2009). La République Démocratique du Congo poscoloniale: du scandale géologique au scandale de guerres à répétition. En Mbuyi, K. y Luque, (coords.): La République Démocratique du Congo. La 
droit humains, les conflits et la construction/destruction de l'Etat. Barcelona: Fundació Solidaritat UB et Inrevés, p.32.

Ndaywell È Nziem, I. (1998). Du Congo des rébellions au Zaïre des pillages. En Cahiers d'Études Africaines (150-152) 418-419.

Kant, I. (1998). Sobre la paz perpetua, (Sexta edición). Madrid: Tecnos.

Organización de las Naciones Unidas, (1945). La Carta de las Naciones Unidas, San Francisco, art. 2.1.

Pardo, J. y Vacas, F. (2005). Los conflictos Internacionales contemporáneos. El conflicto de los Grandes Lagos, Madrid: Ministerio de la Defensa.

Péan, P. (2010). Carnages, les guerres secrètes de grandes puissances en Afrique, Paris: Fayard.

Sánchez, B. P. (2014). Países emergentes vs países menos desarrollados. Éxitos y fracasos, Universidad de Almería (trabajo de fin de grado).

Soto, R. (2003). "La corrupción desde una perspectiva económica”, en Estudios Públicos, (89) 23-62.

Stigliz, J. E. (2012). El presión de la desigualdad, el 1\% de la población tiene lo que el 99\% necesita. México: Ed. Taurus 